\title{
Use of Microballoon Catheter in Transarterial Ethanol Embolization of Renal Angiomyolipoma: A Retrospective Comparative Study with Historical Control?
}

\author{
1) Department of Radiology, Hyogo College of Medicine, Japan \\ 2) Department of Radiology, Mie University School of Medicine, Japan
}

Junichi Taniguchi ${ }^{1)}$, Haruyuki Takaki ${ }^{1)}$, Yuichi Sugino ${ }^{2}$, Nahomi Yoshimura ${ }^{1)}$, Ryo Kunimoto ${ }^{1)}$, Hiroyuki Yokoyama $^{1)}$, Taiki Moriyama ${ }^{1)}$, Naoya Kinota ${ }^{1)}$, Yoshie Inao ${ }^{1)}$, Mitsunari Maruyama ${ }^{1)}$, Atsushi Ogasawara $^{1)}$, Hiroshi Kodama ${ }^{1)}$, Yasukazu Kako ${ }^{1)}$, Kaoru Kobayashi' ${ }^{1)}$ Koichiro Yamakado ${ }^{1)}$

\begin{abstract}
Purpose: To clarify the utility of microballoon catheter in renal arterial ethanol embolization of renal angiomyolipoma (AML).

Material and Methods: A total of 20 patients (15 women, 5 men) with median age of 45 years (39-60 years) underwent embolization to treat 22 AMLs. A mixture of ethanol and iodized oil was injected into the feeding arteries of 13 tumors using balloon occlusion (the balloon embolization group) with a microballoon catheter and 9 tumors without using balloon occlusion (the non-balloon embolization group). Changes in the maximum tumor diameter, tumor volume, and adverse events were evaluated.

Result: The median baseline maximum tumor diameters and volumes were $6.3 \mathrm{~cm}$ and $61.4 \mathrm{~cm}^{3}$ in the balloon embolization group, and $4.6 \mathrm{~cm}$ and $40.1 \mathrm{~cm}^{3}$ in the non-balloon embolization group, respectively. Tumor enhancement disappeared on postembolization angiography in all cases. All tumors shrunk after embolization. There were no statistically significant differences in the percent decrease in the maximum tumor diameter and volume at 10-12 month between balloon occlusion group (31.5\% and 67.9\%) and control group (34.8\% and 62.6\%). Fever was significantly more frequent when balloon occlusion was used: $38 \%$ vs. $0 \%$ ( $p$ $=0.03$ ). No major complication was observed in either patient group.

Conclusions: Balloon occlusion may not affect tumor shrinkage when embolizing AMLs with a mixture of ethanol and lipiodol.
\end{abstract}

Key words: renal angiomyolipoma, renal arterial embolization, balloon occlusion, a mixture of ethanol and lipiodol

(Interventional Radiology Advance Publication)

\section{Introduction}

Renal angiomyolipoma (AML), a benign renal tumor, includes variable amounts of thick-walled blood vessels, smooth muscles, and fat $[1,2]$. Spontaneous rupture and hemorrhage are the most serious symptoms of renal AML $[3,4]$. Tumor size of $4.0 \mathrm{~cm}$ or larger and aneurysm size of
$0.5 \mathrm{~cm}$ or larger are reported as predictors of spontaneous rupture [3, 5].

Renal arterial embolization is a useful therapeutic option for preventing tumor growth, spontaneous rupture, and hemorrhage of AML [6]. Although various embolic agents, such as ethylene vinyl alcohol copolymer, polyvinyl alcohol, coils, gelatin sponge particles, and microspheres, have been used, ethanol is a widely used embolic material for the treat- 
Table 1. Patient Characteristics and RAE Procedures in Each Group.

\begin{tabular}{|c|c|c|c|}
\hline & $\begin{array}{c}\text { Balloon } \\
\text { embolization } \\
\text { group } \\
(n=11)\end{array}$ & $\begin{array}{l}\text { Non-balloon } \\
\text { embolization } \\
\quad \text { group } \\
(n=9)\end{array}$ & $\mathrm{P}$ value \\
\hline \multicolumn{4}{|l|}{ Patient characteristics } \\
\hline \multicolumn{4}{|l|}{ Age } \\
\hline Median & 47 & 39 & 0.40 \\
\hline Range & $41-59$ & $35-61$ & \\
\hline Female/ male & $7 / 4$ & $8 / 1$ & 0.19 \\
\hline Tumor number & 13 & 9 & \\
\hline \multicolumn{4}{|l|}{ Tumor size } \\
\hline Median (cm) & 6.3 & 4.6 & 0.33 \\
\hline Range (cm) & $4.3-8.1$ & $4.0-6.8$ & \\
\hline$>4 \mathrm{~cm} / \leq 4 \mathrm{~cm}$ & $9 / 2$ & $7 / 2$ & 0.68 \\
\hline \multicolumn{4}{|l|}{ Tumor volume } \\
\hline Median (mL) & 61.4 & 40.1 & 0.57 \\
\hline Range (mL) & $32.8-236.1$ & $30.9-114.3$ & \\
\hline Low-fat/ High-fat & $6 / 7$ & $3 / 6$ & 0.36 \\
\hline Unilateral/ Bilateral & $7 / 4$ & $9 / 0$ & 0.02 \\
\hline Single/ Multiple & $5 / 6$ & $8 / 1$ & 0.02 \\
\hline $\mathrm{eGFR}\left(\mathrm{mL} / \mathrm{min} / 1.73 \mathrm{~m}^{2}\right)$ & 85.3 & 80.6 & 0.32 \\
\hline \multicolumn{4}{|l|}{ RAE procedures } \\
\hline \multicolumn{4}{|l|}{ Amount of ethanol } \\
\hline Median (mL) & 6.0 & 2.4 & 0.01 \\
\hline Range (mL) & $3.0-7.5$ & $1.7-4.2$ & \\
\hline \multicolumn{4}{|l|}{ Pecentage of ethanol } \\
\hline Median (\%) & 80.0 & 83.0 & 0.05 \\
\hline Range (\%) & $75.0-82.0$ & $80.0-91.0$ & \\
\hline Total No. of embolized arteries & 20 & 15 & \\
\hline Mean No. of embolized artery per tumor & 1.5 & 1.7 & 0.92 \\
\hline
\end{tabular}

RAE, renal artery embolization; eGFR, estimated glomerular filtration rate

Continuous variables are presented as median values (interquartile range)

ment of AMLs [5-15]. It is a permanent embolic material that is easy to use. However, migration of ethanol can cause complications such as bowel infarction, renal infection, and spinal injury [16-18]. It becomes radiopaque by adding iodized oil, preventing migration of ethanol into the normal renal parenchyma. Development of microcatheters makes it easier to inject ethanol selectively into the arteries feeding a tumor. Furthermore, the advent of microballoon catheters might enable not only selection of tumor feeding arteries but also injection of ethanol forcefully without migration into the normal renal parenchyma to prevent complications [5]. Despite this expectation, the usefulness of using microballoon catheter during embolization of AML has not been fully evaluated.

We retrospectively evaluated the efficacy and safety of renal arterial ethanol embolization of renal AML using microballoon catheter in comparison with those without using microballoon catheter.

\section{Material and Methods}

\section{Patients}

This retrospective study was approved by our institutional review board. Written informed consent to participate in this study was waived due to the retrospective nature of this study.

During April 2009-December 2018, 29 consecutive patients received renal arterial embolization for the treatment of AML at two institutions. Indication for renal arterial embolization includes AML measuring $4 \mathrm{~cm}$ or more, growing tumor with a growth rate of $0.25 \mathrm{~cm}$ per year or more, or a ruptured AML [19]. Among them, nine patients without scheduled follow-up imaging were excluded. A total of 20 patients $(69.0 \%, 20 / 29)$ were included in this study.

Subjects were 5 men and 15 women with median age of 45 (39-60) years (Table 1). Tuberous sclerosis was associated in 2 patients. Everolimus therapy had been performed before embolization in one patient. Diagnosis of renal AML was made of 11 patients using CT and/or magnetic resonance (MR) imaging according to the imaging criteria de- 

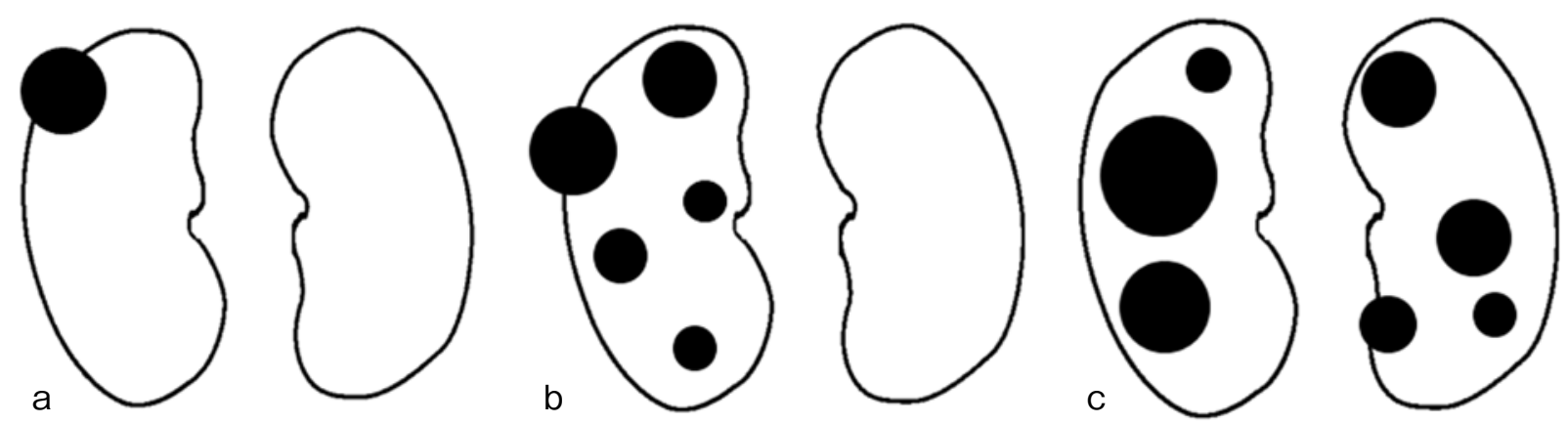

Figure 1. The illustrations to explain the distribution of the real tumors.
a. A single tumor in unilateral kidney.
b. Multiple tumors in unilateral kidney.
c. Multiple tumors in bilateral kidneys.

scribed previously [20]. Biopsy was performed for 9 patients to confirm the diagnosis of AML because imaging findings were not typical. Thirteen patients had single AML (65.0\%, 13/20) (Fig. 1a). Of the seven patients with multiple AMLs $(35.0 \%, 7 / 20)$, three had multiple AMLs $(15.0 \%, 3 / 20)$ in unilateral kidney and four had multiple AMLs in bilateral kidneys $(20.0 \%, 4 / 20)$ (Fig. 1b and c). When patients had multiple AMLs, renal arterial embolization was performed for the largest, growing, or ruptured tumors. Renal arterial embolization was performed for 22 AMLs with median size of $5.2 \mathrm{~cm}(4.1-7.6 \mathrm{~cm})$.

In this study, patients were divided into two groups according to the embolization procedure; 11 patients who received arterial embolization under balloon occlusion with a microballoon catheter (Attendant Delta ${ }^{\circledR}$, Terumo Clinical Supply Co, Ltd, Gifu, Japan and Logos ${ }^{\circledR}$; Piolax Medical device Inc., Kanagawa, Japan) were categorized as the balloon embolization group, and 9 patients without balloon occlusion were categorized as the non-balloon embolization group. The microballoon catheter became available on March 2013. Therefore, microballoon catheter was used in patient who received renal arterial embolization after March 2013 and they were categorized as the balloon embolization group.

The median maximum diameter of AMLs was $6.3 \mathrm{~cm}$ $(4.3-8.1 \mathrm{~cm})$ in the balloon embolization group and $4.6 \mathrm{~cm}$ $(4.0-6.8 \mathrm{~cm})$ in the non-balloon embolization group $(p=$ 0.33). The median volume of AMLs was $61.4 \mathrm{~cm}^{3}$ (32.8$\left.236.1 \mathrm{~cm}^{3}\right)$ in the balloon embolization group and $40.1 \mathrm{~cm}^{3}$ $\left(30.9-114.3 \mathrm{~cm}^{3}\right)$ in the non-balloon embolization group ( $p$ $=0.57)$.

Untypical low-fat AMLs were observed in $46.2 \%(6 / 13)$ and $33.3 \%(3 / 9)$ in the balloon and non-balloon embolization groups, respectively ( $p=0.36$ ).

Characteristics of each patient group were summarized in Table 1.

\section{Pretreatment work-up}

All patients received routine physical examinations, laboratory tests including renal function, a chest X-ray, an elec- trocardiogram test, and computed tomography (CT) or MR imaging within 1 month before embolization.

\section{Renal arterial embolization}

Renal arterial embolization was performed under local anesthesia using lidocaine (Xylocaine; AstraZeneca K.K., Osaka, Japan). After a 4-French (Fr) catheter was introduced into a renal artery, angiography was performed to confirm arteries feeding the renal AML. Then, a 1.9-Fr microcatheter (Progreat $\Sigma$; Terumo Clinical Supply Co., Ltd., Gifu, Japan) or a 2.7-Fr microballoon catheter (Attendant Delta ${ }^{\circledR}$, Terumo Clinical Supply Co., Ltd., Gifu, Japan) or 2.9-Fr microballoon catheter $\left(\operatorname{Logos}^{\circledR}\right.$; Piolax Medical device Inc., Kanagawa, Japan) was inserted into the feeding artery. Embolization was performed using a mixture of ethanol (anhydrous ethanol; Mylan Seiyaku Ltd., Tokyo, Japan) and iodized oil (Lipiodol $^{\circledR}$; Guerbet Japan K.K., Tokyo) with a ratio of $2: 1$ to $10: 1$. Those mixture rates were decided according to the operator's preference. In this study, all patients received selective embolization from the distal branch of renal arteries. In addition, seven patients received embolization from the capsular artery $(n=7)$. The embolization of renal capsular artery under balloon occlusion was performed for three AMLs. In all these cases, selective arteriography was performed under the balloon occlusion just before embolization to evaluate the potential arterial anastomosis with the neighboring arteries supplying adjacent organs including the colon, adrenal gland, and spine. In addition, ethanol was carefully injected in all cases to avoid the non-target embolization. After injection of some amount of ethanol, the balloon was deflated and arteriography was performed. If tumor enhancement was persistent, the balloon was inflated again, and additional ethanol was injected. Additional embolization by using coils was performed in a ruptured AML in the non-balloon embolization group to prevent further bleeding. It was repeated until the disappearance of tumor enhancement (Fig. 2). A total of 20 arteries were embolized in the balloon embolization group and 15 in the non-balloon embolization group. The mean number of embolized arteries per tumor was comparable between the balloon and non- 

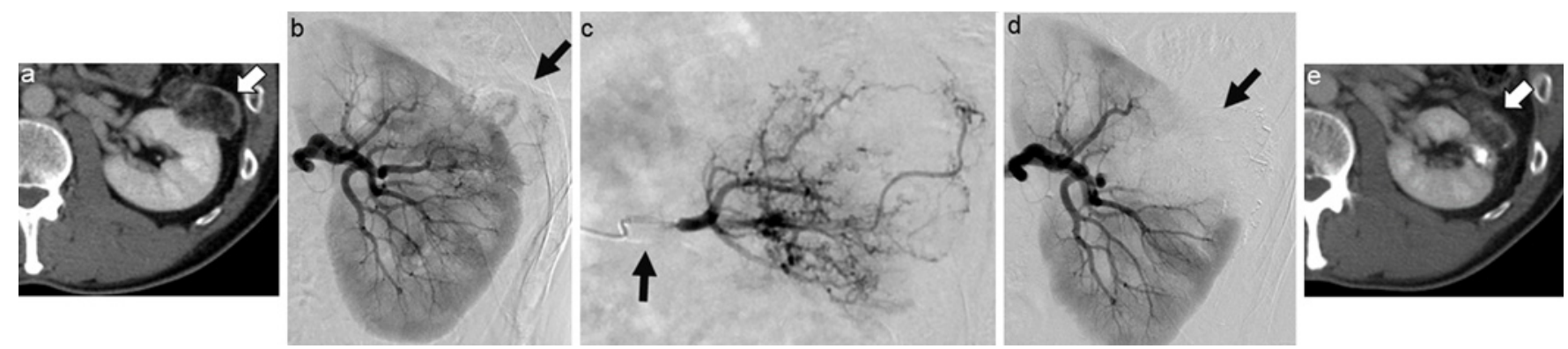

Figure 2. A man in his 50s with an angiomyolipoma (AML) of $49 \mathrm{~mm}$ in the left kidney. a. Nephrographic phase of contrast-enhanced CT before treatment showed AML located at the ventral part of the left kidney (white arrow).

b. Left renal arteriography showed hypervascular tumor (black arrow).

c. Selective arteriography of feeding artery with a microballoon catheter (black arrow).

d. Left renal arteriography after renal arterial embolization with a mixture of ethanol and iodized oil under microballoon inflation showed the disappearance of tumor enhancement (black arrow).

e. Nephrographic phase of contrast-enhanced CT at 12 months after renal arterial embolization demonstrated shrinkage of the tumor size $(38 \mathrm{~mm}$, white arrow).

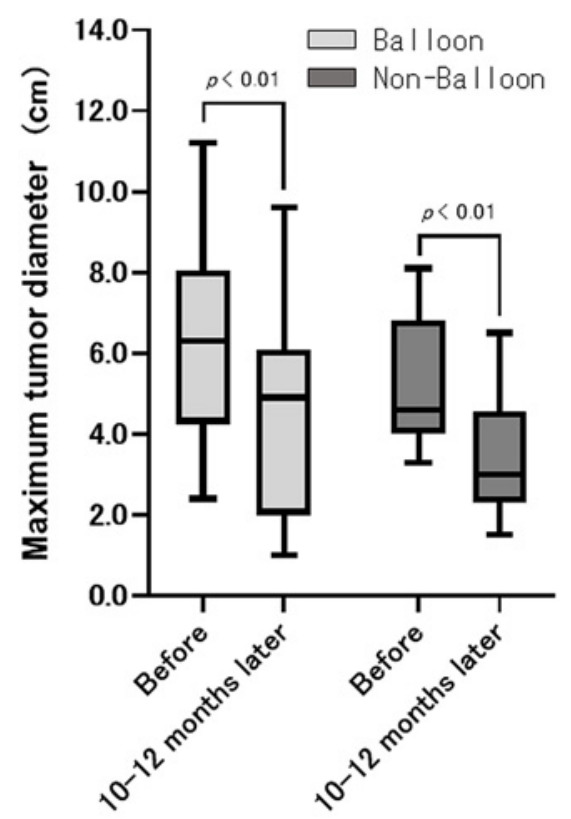

Figure 3. Changes in the maximum tumor diameter after renal arterial embolization.

A median maximum tumor diameter significantly decreased from $6.3 \mathrm{~cm}$ (range, $4.3-8.1 \mathrm{~cm}$ ) to $4.9 \mathrm{~cm}(2.0-6.1 \mathrm{~cm}, p<$ 0.01) at 10-12 months later in the balloon embolization group. In the non-balloon embolization group, it was significantly decreased from $4.6 \mathrm{~cm}(4.0-6.8 \mathrm{~cm})$ to $3.0 \mathrm{~cm}(2.3-4.6 \mathrm{~cm}, p<$ 0.01) at 10-12 months later.

balloon embolization groups (1.5 vs. $1.7, p=0.92)$ (Table 1).

Embolization was performed electively for 18 patients $(90.0 \%, 18 / 20)$ with 20 tumors $(90.9 \%, 20 / 22)$. The remaining two patients $(10.0 \%, 2 / 20)$ received non-elective renal arterial embolization due to the rupture of AMLs. In two patients $(10.0 \%, 2 / 20)$, two renal arterial embolization sessions were performed for each kidney with an interval of 2 weeks and 2 months, respectively.

\section{Follow-up}

Physical examination and laboratory tests including renal function were performed within 1 month after renal arterial embolization and at 1-3 months thereafter. Tumor size and volume were evaluated using CT or MR imaging at 10-12 months after embolization.

\section{Assessment and statistical analysis}

Technical success was defined as completion of planned embolization, and it was evaluated on tumor basis. Tumor size and volume were evaluated at 10-12 months CT or MR imaging follow-up. We calculate the tumor volume using tumor volumetry. Tumor volumetry was analyzed using an application software (ZIOSTATION $2^{\circledR}$; Ziosoft Inc., Tokyo, Japan). The tumor areas on each CT and MR imaging section were calculated using manual tracing by two radiologists (JT and YS) with 4 and 8 years of experience, respectively. The percent decrease in the maximum tumor diameter and volume were calculated by the following formula: \{maximum tumor diameter (or volume) before embolization/maximum tumor diameter (or volume) after embolization $\} \times$ 100. Changes in renal function were evaluated by using the estimated glomerular filtration rate (eGFR) on patient basis. Adverse events including pain, fever, aspartate aminotransferase (AST), and alanine aminotransferase (ALT) increase within 1 week after embolization were recorded and graded according to the Common Terminology Criteria for Adverse Events ver. 5.0 on a patient basis. Changes in the maximum tumor diameter and volume, renal function, and complications after embolization were assessed and compared between the balloon and the non-balloon embolization group.

All continuous data are expressed as a median with an interquartile range in the main text, Table 1 and Fig. 3-7. Comparisons between the balloon and the non-balloon em- 


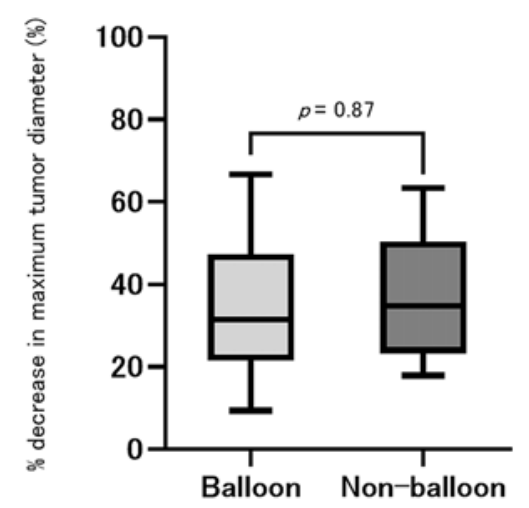

Figure 4. Percent decrease in the maximum tumor diameter after renal arterial embolization.

The percent decrease in the maximum tumor diameter was comparable between the balloon and the non-balloon embolization groups: $31.5 \%(21.5 \%-47.3 \%)$ vs. $34.8 \%$ (23.3\%$50.4 \%)(p=0.87)$ at $10-12$ months later.

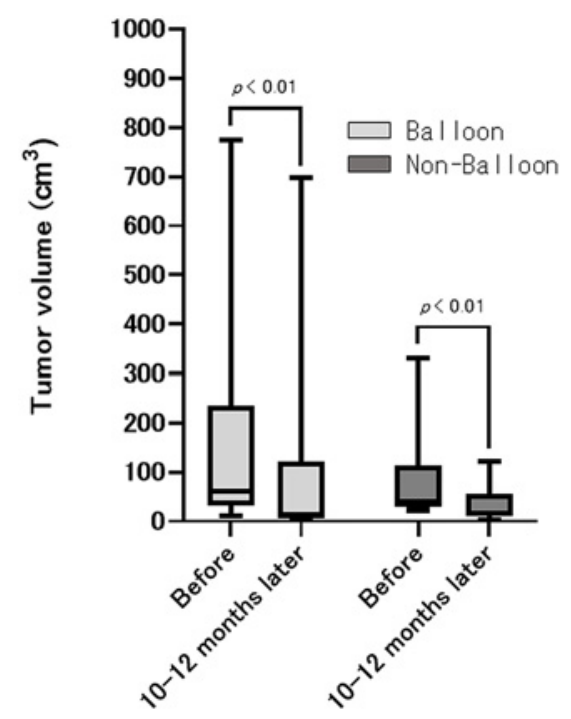

Figure 5. Changes in the tumor volume after renal arterial embolization.

A median tumor volume significantly decreased from $61.4 \mathrm{~cm}^{3}$ (range, $32.8-236.1 \mathrm{~cm}^{3}$ ) to $13.9 \mathrm{~cm}^{3}\left(7.1-121.3 \mathrm{~cm}^{3}, p<0.01\right)$ at 10-12 months later in the balloon embolization group. In the non-balloon embolization group, it was significantly decreased from $40.1 \mathrm{~cm}^{3}\left(30.9-114.3 \mathrm{~cm}^{3}\right)$ to $15.2 \mathrm{~cm}^{3}\left(10.5-57.2 \mathrm{~cm}^{3}, p<\right.$ 0.01) at 10-12 months later.

bolization group were performed using the Mann-Whitney $U$ test and the Wilcoxon's signed rank test for continuous and categorical variables, respectively. All $p$ values less than 0.05 were inferred as significant. All statistical analyses were conducted using software (SAS, release 9.1; SAS Institute Inc., Cary, NC, USA).

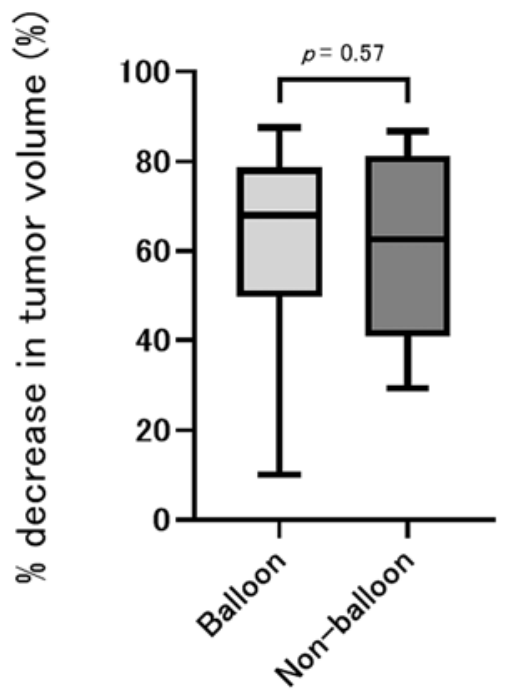

Figure 6. Percent decrease in the tumor volume after renal arterial embolization.

The percent decrease in the tumor volume was comparable between the balloon and the non-balloon embolization groups: $67.9 \%(49.7 \%-78.6 \%)$ vs. $62.6 \%(40.8 \%-81.2 \%)(p=0.57)$ at 10-12 months later.

\section{Results}

\section{Renal arterial embolization}

Tumor enhancement completely disappeared on angiography after renal arterial embolization using ethanol in all cases. Technical success rate was $100 \%$ (22/22). No unexpected normal renal parenchymal embolization was observed in any patient irrespective of the use of microballoon catheter.

More ethanol was injected in the balloon embolization group than in the non-balloon embolization group $(6.0 \mathrm{~mL}$ vs. $2.4 \mathrm{~mL}, p=0.01)$. The median percentage of ethanol in a mixture of ethanol and iodized oil was comparable between the balloon and the non-balloon embolization groups (80.0\% vs. $83.0 \%, p=0.05)$.

\section{Changes in maximum tumor diameter and tumor volume}

A median maximum tumor diameter significantly decreased from $6.3 \mathrm{~cm}$ (range, $4.3-8.1 \mathrm{~cm}$ ) to $4.9 \mathrm{~cm}(2.0-6.1$ $\mathrm{cm}, p<0.01)$ at $10-12$ months later in the balloon embolization group (Fig. 3). In the non-balloon embolization group, it was significantly decreased from $4.6 \mathrm{~cm}$ (4.0-6.8 $\mathrm{cm})$ to $3.0 \mathrm{~cm}(2.3-4.6 \mathrm{~cm}, p<0.01)$ at $10-12$ months later (Fig. 3). The percent decrease in the tumor volume was comparable between the balloon and the non-balloon embolization groups: $31.5 \%(21.5 \%-47.3 \%)$ vs. $34.8 \%(23.3 \%$ $50.4 \%)(p=0.87)$ at $10-12$ months later (Fig. 4).

A median tumor volume significantly decreased from 61.4 $\mathrm{cm}^{3}$ (range, $32.8-236.1 \mathrm{~cm}^{3}$ ) to $13.9 \mathrm{~cm}^{3}\left(7.1-121.3 \mathrm{~cm}^{3}, p<\right.$ 
0.01) at 10-12 months later in the balloon embolization group (Fig. 5). In the non-balloon embolization group, it was significantly decreased from $40.1 \mathrm{~cm}^{3}\left(30.9-114.3 \mathrm{~cm}^{3}\right)$ to $15.2 \mathrm{~cm}^{3}\left(10.5-57.2 \mathrm{~cm}^{3}, p<0.01\right)$ at $10-12$ months later (Fig. 5). The percent decrease in the maximum tumor diameter was comparable between the balloon and the nonballoon embolization groups: $67.9 \%(49.7 \%-78.6 \%)$ vs. $62.6 \%(40.8 \%-81.2 \%)(p=0.57)$ at $10-12$ months later

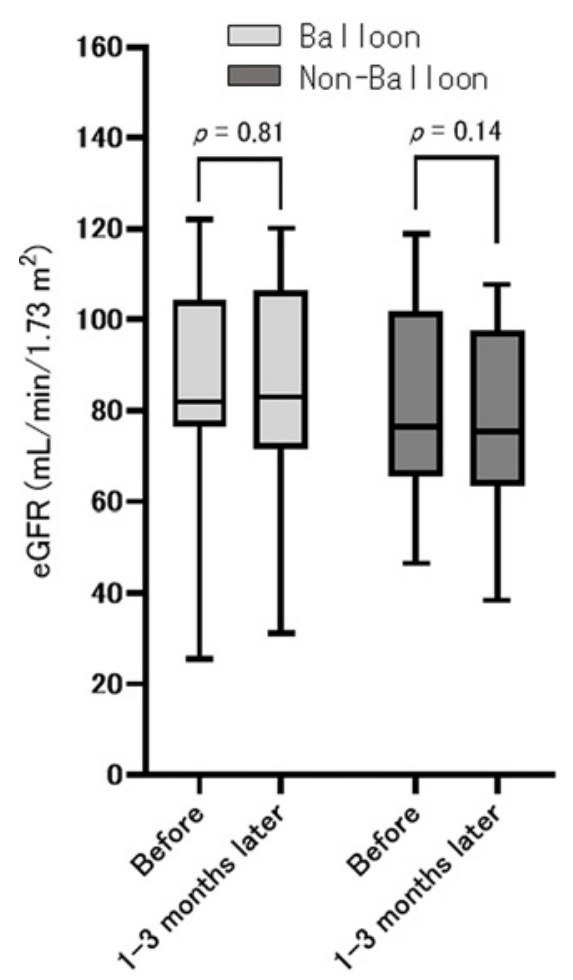

Figure 7. Changes in renal function after renal arterial embolization.

The estimated glomerular filtration rate (eGFR) before and at 1-3 months after renal arterial embolization were $82.0 \mathrm{~mL} /$ $\min / 1.73 \mathrm{~m}^{2}\left(76.4-104.3 \mathrm{~mL} / \mathrm{min} / 1.73 \mathrm{~m}^{2}\right)$ and $83.0 \mathrm{~mL} /$ $\mathrm{min} / 1.73 \mathrm{~m}^{2}\left(\mathbf{7 1 . 5}-106.4 \mathrm{~mL} / \mathrm{min} / 1.73 \mathrm{~m}^{2}\right)$ in the balloon embolization group and $76.4 \mathrm{~mL} / \mathrm{min} / 1.73 \mathrm{~m}^{2}(65.6-101.8 \mathrm{~mL} /$ $\left.\mathrm{min} / 1.73 \mathrm{~m}^{2}\right)$ and $75.3 \mathrm{~mL} / \mathrm{min} / 1.73 \mathrm{~m}^{2}(63.5-97.7 \mathrm{~mL} / \mathrm{min} / 1.73$ $\mathrm{m}^{2}$ ) in the non-balloon embolization group, respectively. No significant change in eGFR before and after renal arterial embolization was observed in either patient group.
(Fig. 6).

\section{Change in renal function}

The eGFR before and at 1-3 months after renal arterial embolization were $82.0 \mathrm{~mL} / \mathrm{min} / 1.73 \mathrm{~m}^{2}(76.4-104.3 \mathrm{~mL} /$ $\left.\mathrm{min} / 1.73 \mathrm{~m}^{2}\right)$ and $83.0 \mathrm{~mL} / \mathrm{min} / 1.73 \mathrm{~m}^{2}(71.5-106.4 \mathrm{~mL} / \mathrm{min} /$ $1.73 \mathrm{~m}^{2}$ ) in the balloon embolization group and $76.4 \mathrm{~mL} /$ $\min / 1.73 \mathrm{~m}^{2}\left(65.6-101.8 \mathrm{~mL} / \mathrm{min} / 1.73 \mathrm{~m}^{2}\right)$ and $75.3 \mathrm{~mL} / \mathrm{min} /$ $1.73 \mathrm{~m}^{2}\left(63.5-97.7 \mathrm{~mL} / \mathrm{min} / 1.73 \mathrm{~m}^{2}\right)$ in the non-balloon embolization group, respectively. No significant change in eGFR before and after renal arterial embolization was observed in either patient group (Fig. 7).

\section{Complications}

No patient experienced grade 3 or more adverse events (AEs). Grade 1 fever developed significantly more frequently after embolization using balloon occlusion (38\%, 5/ 13) than after embolization without using balloon occlusion $(0 \%, 0 / 9, p=0.03)$ (Table 2).

\section{Discussion}

Results of this study indicate that embolization using ethanol mixed with iodized oil is useful in decreasing the tumor diameter and volume irrespective of whether embolic material is injected while using balloon inflation or not. Theoretically, ethanol injection when using balloon occlusion is a more powerful technique than ethanol injection without using balloon occlusion because ethanol can be injected forcibly into the tumor vasculature [5]. Use of microballoon catheter can prevent backflow of the embolic materials (or ethanol) injected from the catheter tip, and therefore it allows injection of larger amount of embolic materials (or ethanol) from a feeding artery. In fact, a greater amount of ethanol was injected when embolization was performed under balloon occlusion. However, the degrees of tumor shrinkage after embolization were almost equal irrespective of the use of the balloon. Recent development of microcatheter technology allows us to navigate a microcatheter deeply into the proper feeding artery. It may also contribute sufficient embolization effect without renal parenchymal injury even without balloon occlusion. Strong embolic power and cytotoxicity of ethanol might be sufficient

Table 2. Adverse Events after RAE.

\begin{tabular}{|c|c|c|c|c|c|c|c|c|}
\hline \multirow[t]{3}{*}{$\begin{array}{l}\text { Adverse } \\
\text { events }\end{array}$} & \multicolumn{4}{|c|}{$\begin{array}{l}\text { Balloon embolization group } \\
\qquad(n=11)\end{array}$} & \multicolumn{4}{|c|}{$\begin{array}{l}\text { Non-balloon embolization group } \\
\qquad(n=9)\end{array}$} \\
\hline & \multicolumn{4}{|c|}{ Grades } & \multicolumn{4}{|c|}{ Grades } \\
\hline & 1 & 2 & 3 & 4 & 1 & 2 & 3 & 4 \\
\hline Fever & $5 *(38 \%)$ & $0(0 \%)$ & $0(0 \%)$ & $0(0 \%)$ & $0 *(0 \%)$ & $0(0 \%)$ & $0(0 \%)$ & $0(0 \%)$ \\
\hline Pain & $5(38 \%)$ & $0(0 \%)$ & $0(0 \%)$ & $0(0 \%)$ & $2(22 \%)$ & $0(0 \%)$ & $0(0 \%)$ & $0(0 \%)$ \\
\hline AST increase & $1(8 \%)$ & $1(8 \%)$ & $0(0 \%)$ & $0(0 \%)$ & $2(22 \%)$ & $0(0 \%)$ & $0(0 \%)$ & $0(0 \%)$ \\
\hline ALT increase & $1(8 \%)$ & $1(8 \%)$ & $0(0 \%)$ & $0(0 \%)$ & $2(22 \%)$ & $0(0 \%)$ & $0(0 \%)$ & $0(0 \%)$ \\
\hline
\end{tabular}

RAE, renal arterial embolization; AST, aspartate aminotransferase; ALT, alanine aminotransferase; * $p<0.05$ 
to control AML and might make it unnecessary to use balloon occlusion to control the tumor.

Since good preservability in renal function after renal arterial embolization has been described in earlier reports of the literature, no significant deterioration in renal function was found after embolization in the present study as well $[21,22]$.

Although severe AEs (grade 3 or more) were not observed in this study, mild (grade 1) fever was observed only after embolization using a balloon catheter. As described above, excessive amount of ethanol may cause fever when injecting ethanol under balloon occlusion.

Given that renal arterial embolization with a mixture of ethanol and iodized oil helps to decrease the tumor diameter irrespective of the use of balloon occlusion, injection of embolic material under balloon occlusion might be associated with the risk of grade 1 fever. Taking the cost of microballoon catheter into consideration, it may not be necessary at the time of renal artery embolization using ethanol in the management of AML.

This study includes several limitations. The retrospective study design examining small number of patients, their inhomogeneous backgrounds, and the short follow-up periods are apparent limitations. Further evaluation with more patient and a longer follow-up time will be necessary to confirm the results of this study.

In conclusion, balloon occlusion may not affect tumor shrinkage for AMLs when performing renal arterial embolization with a mixture of ethanol and iodized oil.

\section{Conflict of Interest: None}

Disclaimer: Haruyuki Takaki is one of the Editorial Board members of Interventional Radiology. This author was not involved in the peer-review or decision-making process for this paper.

\section{References}

1. Wagner BJ, Wong-You-Cheong JJ, Davis CJ Jr. Adult renal hamartomas. Radiographics 1997; 17: 155-169.

2. Jinzaki M, Silverman SG, Akita H, Nagashima Y, Mikami S, Oya M. Renal angiomyolipoma: a radiological classification and update on recent developments in diagnosis and management. Abdom Imaging 2014; 39: 588-604.

3. Yamakado K, Tanaka N, Nakagawa T, Kobayashi S, Yanagawa M, Takeda K. Renal angiomyolipoma: relationships between tumor size, aneurysm formation, and rupture. Radiology 2002; 225: 7882.

4. Ahn T, Roberts MJ, Navaratnam A, Chung E, Wood S. Changing etiology and management patterns for spontaneous renal hemorrhage: a systematic review of contemporary series. Int Urol Nephrol 2017; 49: 1897-1905.

5. Sawada Y, Shimohira M, Hashizume T, Sobue R, Mori S, Nakagawa $\mathrm{M}$, et al. Transcatheter arterial embolization for renal angiomyolipoma using a micro-balloon catheter and a mixture of ethanol and lipiodol. Cardiovasc Intervent Radiol 2017; 40: 19331939.

6. Murray TE, Lee MJ. Are we overtreating renal angiomyolipoma: a review of the literature and assessment of contemporary manage- ment and follow-up strategies. Cardiovasc Intervent Radiol 2018; 41: 525-536.

7. Urbano J, Paul L, Cabrera M, Alonso-Burgos A, Gómez D. Elective and emergency renal angiomyolipoma embolization with ethylene vinyl alcohol copolymer: feasibility and initial experience. J Vasc Interv Radiol 2017; 28: 832-839.

8. Bishay VL, Crino PB, Wein AJ, Malkowicz SB, Trerotola SO, Soulen MC, et al. Embolization of giant renal angiomyolipomas: technique and results. J Vasc Interv Radiol 2010; 21: 67-72.

9. Han YM, Kim JK, Roh BS, Song HY, Lee JM, Lee YH, et al. Renal angiomyolipoma: selective arterial embolization-effectiveness and changes in angiomyogenic components in long-term followup. Radiology 1997; 204: 65-70.

10. Lee SY, Hsu HH, Chen YC, Huang CC, Wong YC, Wang LJ, et al. Embolization of renal angiomyolipomas: short-term and longterm outcomes, complications, and tumor shrinkage. Cardiovasc Intervent Radiol 2009; 32: 1171-1178.

11. Takebayashi S, Horikawa A, Arai M, Iso S, Noguchi K. Transarterial ethanol ablation for sporadic and non-hemorrhaging angiomyolipoma in the kidney. Eur J Radiol 2009; 72: 139-145.

12. Rimon U, Duvdevani M, Garniek A, Golan G, Bensaid P, Ramon $\mathrm{J}$, et al. Ethanol and polyvinyl alcohol mixture for transcatheter embolization of renal angiomyolipoma. AJR Am J Roentgenol 2006; 187: 762-768.

13. Thulasidasan N, Sriskandakumar S, Ilyas S, Sabharwal T. Renal angiomyolipoma: mid- to long-term results following embolization with onyx. Cardiovasc Intervent Radiol 2016; 39: 1759-1764.

14. Patatas K, Robinson GJ, Ettles DF, Lakshminarayan R. Patterns of renal angiomyolipoma regression post embolisation on medium- to long-term follow-up. Br J Radiol 2013; 86, issue 1024.

15. Lenton J, Kessel D, Watkinson AF. Embolization of renal angiomyolipoma: immediate complications and long-term outcomes. Clin Radiol 2008; 63: 864-870.

16. Teertstra HJ, Winter WA, Frensdorf EL. Ethanol embolization of a renal tumor, complicated by colonic infarction. Diagn Imaging Clin Med 1984; 53: 250-254.

17. Bishay VL, Crino PB, Wein AJ, Malkowicz SB, Trerotola SO, Soulen MC, et al. Embolization of giant renal angiomyolipomas: technique and results. J Vasc Interv Radiol 2010; 21: 67-72.

18. Lammer J, Justich E, Schreyer H, Pettek R. Complications of renal tumor embolization. Cardiovasc Intervent Radiol 1985; 8: 3135.

19. Bhatt JR, Richard PO, Kim NS, Finelli A, Manickavachagam K, Legere L, et al. Natural history of renal angiomyolipoma (AML): most patients with large AMLs $>4 \mathrm{~cm}$ can be offered active surveillance as an initial management strategy. Eur Urol 2016; 70: 85-90.

20. Buj Pradilla MJ, Martí Ballesté T, Torra R, Villacampa Aubá F. Recommendations for imaging-based diagnosis and management of renal angiomyolipoma associated with tuberous sclerosis complex. Clin Kidney J 2017; 10: 728-737.

21. Williams JM, Racadio JM, Johnson ND, Donnelly LF, Bissler JJ. Embolization of renal angiomyolipomata in patients with tuberous sclerosis complex. Am J Kidney Dis 2006; 47: 95-102.

22. Ramon J, Rimon U, Garniek A, Golan G, Bensaid P, Kitrey ND, et al. Renal angiomyolipoma: long-term results following selective arterial embolization. Eur Urol 2009; 55: 1155-1161.

Interventional Radiology is an Open Access journal distributed under the Creative Commons Attribution-NonCommercial 4.0 International License. To view the details of this license, please visit (https://creativecommons.org/licenses/by$\mathrm{nc} / 4.0 /)$. 
Interventional Radiology Advance Publication 